\title{
10
}

\section{NEW ORSIAM INT'L : A progressive management dynamics game focused on operations research and decision sciences in industrial management.}

\author{
H. Muller(-Malek), P. Vanderschaeghe, H. Vanmaele
}

\author{
University of Ghent - Department of Industrial Management \\ Technologiepark Zwijnaarde 9 \\ B-9052 Ghent \\ Belgium
}

Tel : $(+32) 9264.55 .02$

Fax : (+32) 9264.58 .47

e-mail : Hendrick.Vanmaele@rug.ac.be

\begin{abstract}
.
New Orsiam Int'l is a career oriented management dynamics game in which different companies, consisting of three to six participants, operate in a common and interactive industrial environment. They are facing a progressive enlargement of the problem area, a broadening decision horizon and an increasing hierarchical responsibility while going through a "typical" engineer career.

During the Orsiam-sessions, the emphasis is not only on the transfer of theoretical knowledge, but rather on allowing the participants to acquire skills in and to improve the integration and understanding of previously studied theories and techniques of decision sciences, operations research, systems management, engineering economics and general industrial management topics of procurement, production and personnel management, marketing and financial management.

Within the New Orsiam Int'l course framework, much attention is also given to the continuing feed back which is the result of the fully automated multicriteria evaluation procedure.
\end{abstract}

Keyword codes : H.4.0. ; I.6.3. ; J.2. ; K.3.1.

Keywords : Information systems applications ; Simulation and modelling, applications ; Computer applications in engineering ; Computer uses in education. 


\section{Introduction.}

The career oriented management dynamics game New Orsiam Int'l has been developed at the Department of Industrial Management of the University of Ghent, chaired by Prof. ir. H. Muller(-Malek). The improvements, enhancements and updating of the game since the project was initiated in the early seventies has been funded by several research projects that have been carried out under the guidance of Prof. Muller(-Malek).

This paper intends to point out the specific goals of the game, to give a general introduction to the game concept and a short description of the main parts of this modular game. In the last chapter, we will mention some experiences that were gathered during the many times New Orsiam Int'l has been played in several settings.

\section{Goals and focus of the management dynamics game.}

New Orsiam Int'l has been developed as a computer assisted, progressive career oriented management dynamics game in which teams of three up to six participants (called companies) are operating as industrial high-tech computer toys manufacturers on common markets of four up to six companies.

The general course framework, which is built around the New Orsiam game, is developed in order to further the integration of theories and techniques which have been taught previously in the domain of operations research, decision sciences, information retrieval and analysis, systems management, marketing, financial management and general industrial management topics such as procurement, maintenance, line balancing, scheduling, internal and external logistics, ...

The main goals of the course are :

1. To give the participants the opportunity to acquire experience and skill in general problem solving techniques. The main focus is on identifying and analyzing complex and fuzzy problems and on implementing operational solutions which are linked together and are interacting with all elements of a total system structure with multicriteria behavioral patterns.

2. To improve the skills of the participants in estimating the relevance and effectiveness of alternative approaches (e.g. holistic versus analytical) and in appreciating the practical usefulness of the corresponding techniques when applied in a complex, dynamic and interacting environment.

3. To demonstrate the use and usefulness of computer assisted planning models, financial spreadsheets and mathematical solvers or optimizers in order to overcome the resistance towards interactive man-machine decision support.

4. To bridge the gap between the participant's idealistic educational world and his future career struggle for survival. One should try to integrate in the course well chosen industry visits or guest speakers with business practice. This is necessary to show the participants the advantages and disadvantages of an industrial setting when it comes to applying the techniques that were acquired in a simulated environment. The main contribution of guest speakers, in particular top managers, is in the fact that they can transfer the required skills, as well as the attitude which is necessary to survive in today's business environment. 
5. To demonstrate the tradeoff between rational theory and techniques on the one hand and the importance of communication skills, human relations and negotiation capacities on the other hand, even in a very quantitative and rationally defined business environment with high rewards for the judicious use of management science techniques. Furthermore, it is emphasized that there is no dichotomy between acceptable and qualitative decision outcomes, but that the latter precedes the former in successful decision processes. In the same sense, we want the participants to understand the necessary recycling movement between analytic and synthetic attitudes during the problem puzzling, the decision process and the action preparation.

\section{Specific focus of the game : a career approach of an industrial engineer (fig. 1).}

The traditional conception of a business game, based on a global and direct confrontation with all elements of the game at the same time, is not the best way of controlling the learning process of the participants. Therefore, New Orsiam Int'l is based on a gradual introduction of the different aspects and difficulties of the complex world. Experience showed that the introduction of the entire complexity at once leads to demotivation of the participants or to playing instead of thinking and analyzing. Such a situation would of course not be beneficial for the understanding and use of decision sciences techniques or for the application of computer assisted planning, nor would this attitude enhance the rational problem solving.

A very important aspect of the game is about controlling the availability of the information, which is gradually growing throughout the game. This is done in order to be more critical about the relevancy of the obtained information, to understand the cost vs. benefit evaluation of supplementary or more sophisticated information and to stress on the necessity of adequate management information systems. Throughout the game, the participants are not motivated to buy as much information as possible, but rather to find out creative ways of relevant data collection.

Enlarging the horizon of the decision making and the growing responsibility throughout the game allows participants to test the relative value and consequences of different techniques of operations research and decision sciences. The growing complexity of the organizational system enables us to give the participants documentary evidence about the specific value of the techniques and to force them into redefining the relevant decision problems that will change from one period to another. This redefinition of the problems together with the growing responsibility will give reason to reconsider the structuring and formulation of the problem and to choose corresponding solution methods in accordance with the new environmental data and the new responsibilities. Gradually, the participants will also realize that a unique objective function of a lower managerial level is unnatural in a business environment of higher managerial responsibilities and that even for a multicriteria approach, it is necessary to change dynamically the formulation. At the same time, they become conscious of the importance of the horizon definition (i.e. how long does a decision make sense if it is taken on specific data), the conceptual difference between a static and a dynamic formulation of a problem and the possible interaction between them, and the decreasing deterministic character of long term decisions. 


\section{COURSE OUTLINE}

\section{Career approach of an industrial engineer}

Fire destroyed part of the manufacturing plant.

As a jobstudent you get the responsibility for the short term production planning.

While rebuilding, why not change the line balancing and quality control systems.

You are engaged as an industrial engineer.

The labour unions disagree with the reorganization plans and request wage increases.

As staff to the plant manager, you get the responsibility for these negotiations.

The plant manager has a near fatal ski-accident.

Enlargement of your responsibilities to purchasing, production and sales in the homeland market.

The capacity expansion problem fits well in your MBA curriculum.

The subject is an ideal thesis subject.

The financial controller retires.

You are promoted to company manager.

Overcapacity calls for large volume orders ; although risky, a solution may be the tendering on international surplus markets.

You are therefore nominated as a board member.

The board of directors discusses long term strategies on the introduction of new products.

You are assigned as project leader for the design of a publicity campaign as well as for the total programme of the new to be launched products.

A possible enlargement of your markets to the European Community calls for additional acquisitions and / or joint ventures.

To be a valuable discussion partner, you get the title of Corporate Executive Officer.

The international demand for high quality standards is not anymore compatible with your production facilities.

You have to launch a Total Quality Assurance campaign.

Due to environmental legislation, some apparently novice raw material has to be withdrawn from the market place.

A shortage of acceptable alternatives brings you the the Raw Material Stock exchange in view of guaranteeing a minimum supply.

Political turmoil (foreign military conflicts) opens a lucrative market for chips.

Will your business ethics allow you to circumvent a UN embargo on this trade?

\section{Figure 1. Career approach of an Industrial Engineer.}



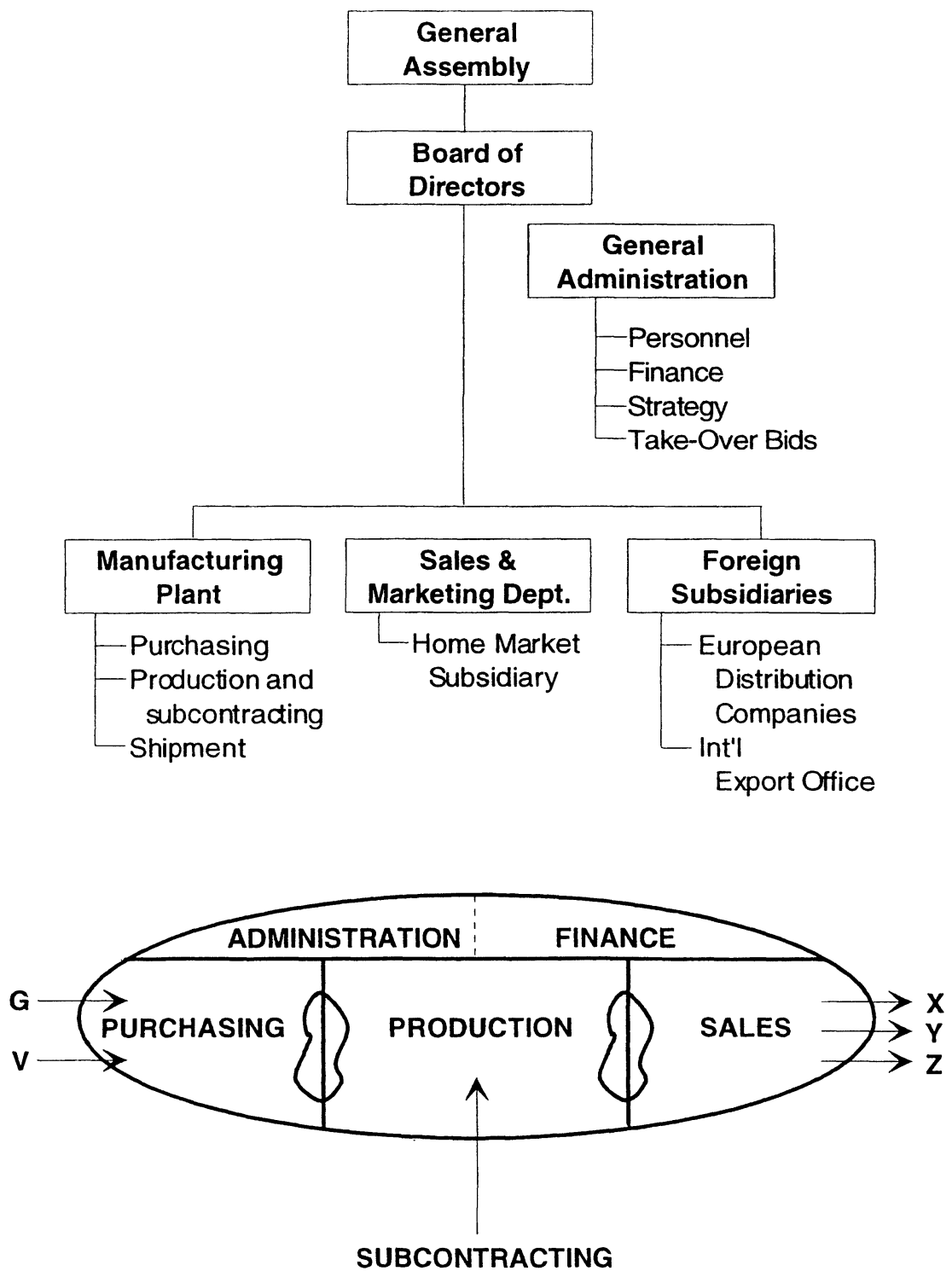

Figure 2. Organizational chart of the New Orsiam Companies. 


\section{The New Orsiam Int'I modular environment.}

The most characteristic part of the New Orsiam Int'l business game is the modular approach. Depending on the level, background and specific interests of the participants, the available time and the setup of the game, different aspects of company management can be emphasized. Because of this modular aspect, the game may be personalized, which also requires more dedication and involvement from the game coordination. The game coordinators play an important role in the game and their task is not limited to pure and simple observation. There is in fact no a priori standard game; the scenario has to be revised every time.

The following paragraphs will give a description of the world in which the game is played and of the different modules that can be included. In theory, the game may be played in a traditional, steady state way, i.e. a series of consecutive identical periods. This is, however, certainly not the best way to transfer the skills and techniques they will need.

After a short introduction of the game (and optionally having played a first standard period), the players divided in companies of three to six persons, have to determine the strategy of their company by attributing different weight factors to six objective criteria. It is very important that each company plays the game according to their own defined strategy.

All companies produce high tech toys (called Xanthippe and Yonai products), which are made from the same two basic raw materials, however in different quantities and requiring different working and machining capacity. Each company has three types of employees : workers, foremen and quality managers. The work pace and the quality of the products are function of the working circumstances (workload, wages, promotion policy, ...).

During the first period of the game, the participants are responsible for optimizing the production mix of their company taking into account the available resources and their strategy.

After this first session, run after run, the responsibility of the players is enlarged gradually starting from production but soon going to personnel management, sales and marketing, finance etc... The organizational chart of the New Orsiam companies is pictured in figure 2. The order, in which the different responsibilities are introduced, is a function of the pursued career plan and has to be determined by the game coordinators.

In the field of sales and marketing, one to three different markets (fig. 3) can be added to the game, each one of them according to different market principles. The basic market which is called home market, operates according to basic market principles such as price, publicity, credit, seasonal fluctuation, ... A creativity exercise can be included her by having the participants draw up an advertising campaign. The second market, also called international surplus market, operates according to the principles of tendering with large volumes, low margins and important risks. The third market (European Community Market) is based on reaching new customers with the existing products through product differentiation in function of their own product perception and the permanently evolving product specification images. Therefore the companies have to take over small firms to do the adaptations. This module requires additional efforts from the participants, as they have to take into account the financial feasibility and the competitive availability of the possible take-over as well as a large number of marketing decisions.

Different modules can be added in the field of production as well. In the basic version, there is the problem of the optimal use of the production facilities (for this purpose, the participants 


\section{ORSIAM Markets}

\section{Home Market}
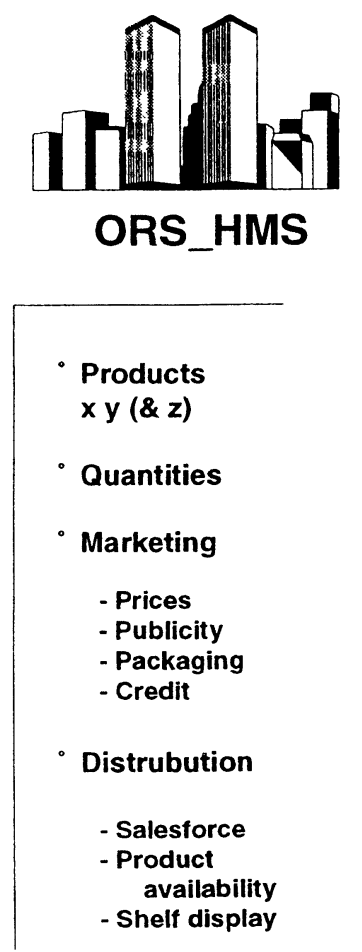
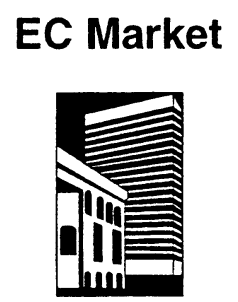

ORS_EDC

\section{Int'I Market}

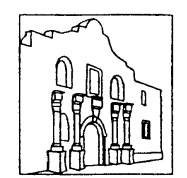

ORS_IEO

Figure 3. New Orsiam Int'l markets structure.

have at their disposal a video-gaming like shopfloor simulator, called OPT_SIM). Other important additional problems are the quality department management, a strike of the workers, a method study of the plant, a shortage of raw materials, the introduction of the new product, called Zwingli, investment in new machines, multiple shifts, ... . In many cases, these problems require different skills, such as negotiating skills (strike), financial investment analysis, understanding the implications of the strategy, ... . 
For each decision they take, the players also have to take into account the economic and financial aspects of their company. The players have to be aware of the impact of their decisions on their balance sheet, yearly account and on the cash position. Companies that are short of liquid assets, can ask for credit ; companies with good results have different possibilities to invest their money (bank deposit, bonds, shares).

During the game, the social skills of the participants are constantly appealed to, not only during certain stages in the game (cfr. to avoid strike, during bargaining sessions, in the case of shortage of raw materials), but also during time pressured group work in their companies. The way the work is organized, certainly is a good experience for a lot of people. Moreover the final evaluation of each company is linked to a final assignment which includes the presentation of annual reports of their company to the general meeting of shareholders (i.e. the game coordinators).

\section{The automated multicriteria evaluation procedure.}

For a simulation and gaming course approaching business reality, a multicriteria evaluation of the participating groups is absolutely necessary. The objective judgment must be done against a real business background and based on considerations regarding production, marketing, finance, economics, social affairs and societal aspects.

A highly automated evaluation procedure is therefore indispensable. In fact, because of the complexity of the whole system and without a robust and objective evaluation procedure, we have :

1. The danger of too subjective evaluation by the referee(s).

2. A problem in keeping the evaluation reference constant in time, due to the ever changing span of control and responsibility, decision horizon and available information.

3. Difficulties in assuring consistency in the mutual comparison of the different participants.

4. A tremendous amount of computational work due to differentiated group objectives.

5. The danger of a partial and one-sided education because of a one-sided evaluation of the results on a too narrow reference scale, if we would oversimplify a dynamic multicriteria problem situation towards pure economic aspects.

The New Orsiam Int'l evaluation procedure is based on six major criteria, also called strategy objectives. It is by weighing these objective criteria that the participating groups individually quantify their company policies.

The objective criteria included in the automatic evaluation procedure are :

1. Operational Efficiency, mainly influenced by the optimization of the production process and based on notions, such as productivity, machine efficiency, los ‘ production hours, sales per worker, operational security index and inventory turnover ratio, $\left.t_{1} ..\right\urcorner$ inventory level of raw materials and finished goods.

2. Marketing Ability, i.e. the control of clients and market environment, based on notions as market share, price index, advertising index, gross profit margin, sales budgeting, accuracy of demand forecast and forecast of market share. 
3. Economic Results, i.e. the traditional globalized appreciations of short and medium term management, based on notions as profit, operating profit margin, security index, retuin on investment, turnover ratio, cash flow ratio, surplus value.

4. Financial Independence, i.e. mainly the task of medium term management and aiming at decision freedom from the financial viewpoint. This is based on notions as cash shortage or surplus funds, acid test, debt ratios, working capital ratios, auto-financing.

5. Social Implications, i.e. a measure of the employees' satisfaction at the expenses of which high operations efficiency and excellent economical results should not be obtained. This is based on notions as promotion opportunity, wage and salary increase, own production ratio.

6. Political Power, i.e. implication of managerial decisions on the environmental appreciation and local government reaction, based on notions as added value, capital invested, company size, credit line, employee qualification, number of employees, perished raw materials.

Marks for these objective criteria and a global result are calculated in the following way. For all six criteria together, about 96 basic data, called observations, are gathered for each period and for each company within the game. These observations result in marks based on either ranking or scaling.

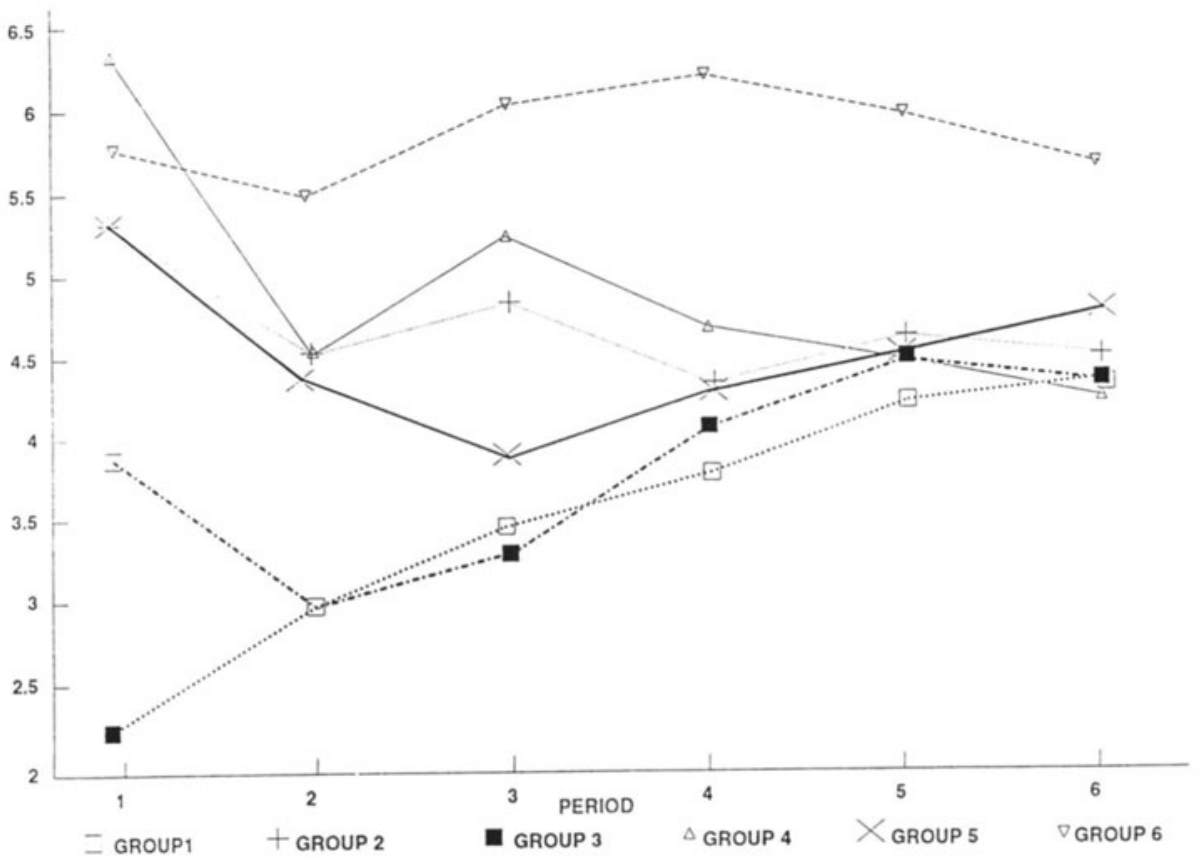

Figure 4. Example output of the automated evaluation module. 
A general mark for each objective criterion is obtained by making a weighted average of the included observation marks. The weights used for this purpose can be fixed differently in each period. An adequate setting of these weights by the game coordinator, makes it possible to obtain a hierarchical evaluation structure parallel to the hierarchical structure of the decision processes in real business. To facilitate the understanding and interpretation of ratings, the (modular) company is subdivided in six responsibility areas (functional units) with intra-units transfer prices. Finally, a global period mark is obtained by making a weighted average of the objective criteria marks (fig. 4). As the different participating groups pursue different policies, they are allowed to specify beforehand the weight of the different objective criteria.

In order to have a smoothed result allowing to see the progress made so far, a weighted average is made of the previous marks on each observation, each objective criterion and the global result. In parallel with the global results for each of the different companies, the referee obtains for each group the global evaluation with the respective weights of the other groups, this in order to compare their own chosen strategy with the achievement of each competing group. A measure of the consistency in decision making according to the defined strategies is obtained by comparing the global result calculated using the participants' own weights with the result computed using neutral weights, equal for all objective criteria.

\section{Conclusions and experiences with the career oriented management dynamics game.}

Obviously, a complete description of New Orsiam Int'l would be extremely complex, because there are no two games that are completely identical. This is the force as well as the weakness of the game. New Orsiam Int'l can provide the players with a large spectrum of techniques and experiences, but it largely depends on the motivation and the dedication of the game coordinators. There is a lot of interaction between game coordinators and participants, which requires a lot of flexibility and involvement from both groups. The gradual increase of the decision capacity of the participants and the modularity of the game is rather unique, which has large advantages.

New Orsiam Int'l is currently taught by Prof. H. Muller(-Malek) as a business simulation laboratory at the University of Ghent (School of Engineering), as well as at the State University of Antwerp. Previous versions of the game are also used at the Vlerick School of Management (Ghent), at the Catholic University of Louvain (Applied Economics) and at the Institute of Higher Economic Education (Brussels). French versions are used at the University of Mons and at the University of Namur. The English version of the game was developed wigthin the framework of an exchange agreement with the London School of Business. The latest English versions are currently used at the Limburg University Center (Belgium), the Technical University of Twente (The Netherlands), the Zeeland School of Higher Education in Vlissingen (The Netherlands) within an Erasmus-cooperation with Spain and at the Flemish University Center of Brussels for a Tempus-cooperation with Poland. Since 1993, the game New Orsiam Int'l has been used for the first time in a non-Western economic environment by the Technical University of Riga (Latvia).

During the numerous runs which have been done using this business game, some interesting observation have been made for example concerning the differences in attitude between mangers in post-experience courses and post-graduate students : 
1. Managers are better in problem diagnosis but tend to underestimate the importance of the decision models and computer support. Students on the contrary play with the decision support and experience often the fact that too much attention to the algorithm may give a good solution for the wrong or not relevant problem.

2. Managers mostly take a very critical attitude towards facts and figures. They rather like to use their personal experience and opinions. Students never question figures. They have, however, difficulties in filtering out relevant information from an abundance of data.

3. Time pressure works entirely different on both groups. Managers often forget in the last five minutes all their decision preparation and just take a decision, they had already in their mind at the beginning of the time period. Students tend to repeat the decisions of a previous decision period for those problems which could not be fully investigated due to lack of time.

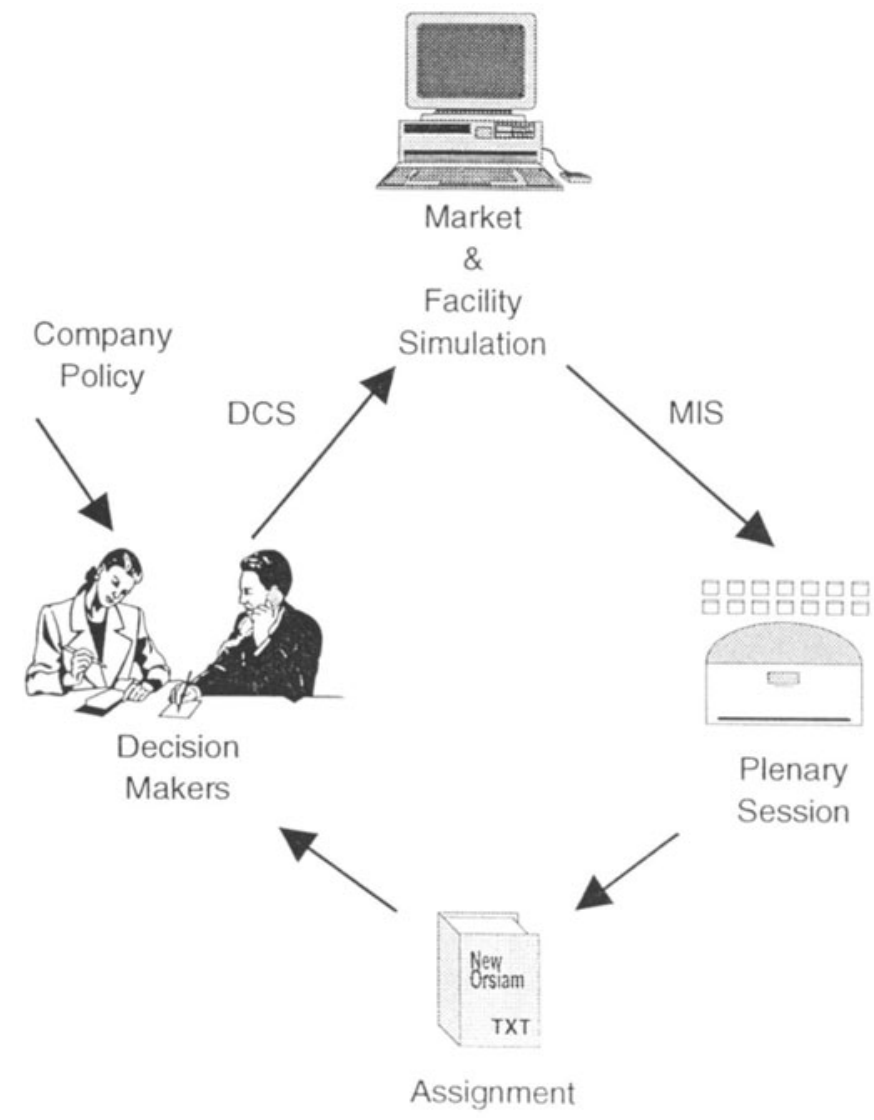

Figure 5. Information flow in the New Orsiam Int'l approach. 
By means of a debriefing and general discussion session after each decision period, the participants learn to understand, to compare and to evaluate each other's approaches. In this way they get familiar with an information flow approach as pictured in fig. 5. This has a tremendous creative effectiveness as stepwise presented criticism is easier accepted than closing referee remarks. It is through these discussion sessions that the teaching objective can be achieved and not by just playing the business game.

Without the evaluation procedure these group discussions would not reveal the true reasons of exceptional performances. Multiple performance criteria reduce ambiguity and help understanding the cause-effect relationships inherent in a business environment. As social and societal aspects are part of each business environment, an appreciation of these aspects must and has been included in the game and its evaluation procedure. 